\title{
Jósef Stalin y los ritos de poder: continuidad e infalibilidad, 1929-1953
}

Joseph Stalin and Power Rites: Continuity and Infallibility, 1929-1953

Sebastián Román Vidal*

El georgiano Jósef Stalin es una de las figuras más estudiadas e influyentes del siglo XX. Sobre él se ha publicado tanto que se hace imposible recopilar todo lo disponible actualmente, y que incluye biografías, libros de historia e incluso novelas (Lourie, 2001). Imposible es también hablar de la historia de Rusia sin mencionarle, omitirle al tratar la Segunda Guerra Mundial, la Guerra Fría; hasta una crónica de la Revolución Rusa quedaría a medio camino sin él. Es en este aspecto que subyace la dificultad de tratar a un personaje ya tan retratado, en que la abundancia de material suele poner trabas al abordaje de este tipo de temas.

Dificultades más, dificultades menos, hemos optado por abordar al personaje desde una perspectiva relacionada con la nueva historia política, en que analizaremos los ritos y simbolismos que permitieron al soviético ascender, acumular y emplear el poder, junto con su trascendencia después de su fallecimiento en el devenir posterior de la Unión Soviética. Para ello, tomaremos de los autores testimonios de las acciones del georgiano tras el fallecimiento de Lenin -en el vacío de poder que deja tras su caída-, en las que se observen intencionalidades con el propósito de obtener y mantener el poder, ya sea que aludan a su conexión con una tradición anterior a la revolución o con el legado de Lenin, y que le permitirían sostener su carácter infalible.

Chileno. Licenciado en Historia y estudiante del Programa de Magíster en Historia, Universidad de Concepción, Chile. E-mail: sebastianroman@udec.cl 


\section{Soso, Koba, Stalin}

Jósef Vissariónovich Dzhugashvili nació el 20 de diciembre de 1879 en el pequeño pueblo de Gori, cerca de Tiflis y el Cáucaso (Payne, 1967: 25). Este ambiente campesino y carenciado sin duda marcaría su vida futura, siendo víctima de las golpizas de su padre alcohólico, testigo de las penurias de su madre y objeto de la compasión de sus vecinosLa viruela que contrajo a los siete años dejó notorias cicatrices en su rostro; a los diez, una infección mal tratada dañó gravemente su brazo izquierdo, quedando encorvado y 7,5 centímetros más corto que el opuesto (Payne, 1967: 28). El único consuelo del pequeño Soso ${ }^{2}$ lo encontraba en la solemnidad del culto ortodoxo. Ya entrando a la mayoría de edad, comenzaría el seminario hasta que, en 1899, cambiaría la cruz de ocho brazos por el socialismo, la pólvora y la sangre, Koba era su primer pseudónimo revolucionario (Laqueaur, 2003: 17), emulando a un héroe de una antigua leyenda georgiana.

Su relevancia en la historia del partido bolchevique fue menor hasta 1917; a pesar de que vivió el encarcelamiento y tomó parte en actividades del partido, no lograba destacar entre ellos. Durante la Guerra Civil (1917-1923) logró tener un papel más importante en la defensa de Tsaritsin. En 1919 fue nombrado miembro del Politburó, tres años más tarde, Secretario General del Partido, un cargo hasta ese momento de poca importancia (Laqueaur, 2003: 20). Desde ese cargo, que mantuvo hasta el fin de sus días, ejercería el poder, en un periodo a grandes rasgos marcado por un omnipresente culto a su personalidad, sustentado por una maquinaria propagandística masiva, encarcelamientos inhumanos en el Gulag, purgas, asesinatos por encargo, juicios públicos dignos de 1984, planes quinquenales de industrialización ineficientes, hambrunas, la conquista de Berlín en el contexto de la Segunda Guerra Mundial y la consolidación de la única potencia capaz de hacer frente a los Estados Unidos durante el siglo XX.

Stalin, el hombre de acero ${ }^{3}$, falleció el 5 de marzo de 1953. Su cadáver embalsamado y sus numerosas medallas son veladas en 
el mausoleo que ahora deberá compartir Lenin. Sus acólitos fieles le acompañan: Molotov, Kaganovich, Bulganin, Voroshilov, Beria, Malenkov, Mikoyan, Zhukov, Sokolovsky, Koniev, Vasilevsky y, en el lugar más alejado del féretro, Krushev, quien le sucedería en el cargo. Los discursos pronunciados ese día fueron predecibles y escasamente emotivos, salvo por Molotov, quien debía detenerse cada tanto a secarse las lágrimas que le impedían leer su texto (Payne, 1967: 580). No sabemos si lloraba de pena o terror ante la incertidumbre del porvenir.

\section{1 de enero de 1924}

Una ilustración de su anguloso rostro en el Pravda, el compromiso de que una ciudad sería rebautizada con su nombre, emotivos discursos y un ausente ${ }^{1}$. Después de una angustiante agonía, el edecán de la Revolución de 1917, el más preclaro intérprete y quien supo mejor adaptar la teoría marxista a la situación rusa, abandonaría el mundo de los vivos y su dacha en el apacible Gorki para tomar residencia en el mausoleo de la Plaza Roja, donde hasta hoy puede ser visitado. Sin embargo, había transcurrido ya un par de años que Vladímir Ilich Uliánov estaba retirado, por mucho que intentó regresar a la vida pública y la política. Durante su retiro, dictó una especie de testamento, una esperanza hacia el futuro del legado que dejaría, en que caracterizaba a los miembros del politburó, líderes del partido que podrían sucederle. A Nikolái Bujarin lo retrató de escolástico y pueril, aunque su heredero más propicio (Laqueaur, 2003: 31); a Trotsky como antisocial y arrogante, a Kámenev y Zinóviev como demasiado moderados, pero, de entre todos, el más peligroso era el georgiano apodado Stalin, demasiado tosco y quien debía ser removido (Kenez, 2006: 7). Irónicamente, él fue quien pareció más conmovido durante el funeral de Lenin (Carr, 1979: 68). Sin embargo, la advertencia de Lenin tuvo pocos oyentes, su enfermedad enmudecía su elocuencia. Afligido y alejado, no tenía posibilidad de ganar la pugna con Stalin, quien ya se había granjeado el apoyo de Zinóviev y Kámenev. Los únicos aliados de Lenin fueron su esposa Nadezhda Krúpskaya, afectada severamente por los nervios, y

Lev Trotsky no asistió al funeral, en parte por sus propias aflicciones, la distancia y la repentina elección de la fecha del evento (Payne, 1967: 289-290). 
su secretaria, cuyas buenas intenciones resultaron insuficientes (Payne, 1967: 249-251).

El vacío de poder tardó en ocuparse. Trotsky se encontraba, si bien no completamente solo, incapaz de hacer frente a la oposición (Laqueaur, 2003: 60); Bujarin tuvo mejores oportunidades, pero ocultó su disidencia, llegando incluso a coincidir con Stalin hasta el fin de la Nueva Política Económica (1929); Kámenev y Zinóviev fueron apartados apenas dejaron de servirle (Payne, 1967: 306). Ninguno de ellos murió de causas naturales.

En este momento, en 1929, el Secretario General del Partido Comunista de la Unión Soviética (Payne, 1967: 236), el georgiano tirano en ciernes, logra hacerse con el poder otorgándole a su cargo, en principio meramente burocrático, atribuciones cada vez mayores. Encontrará bajo su mandato una conjunción étnica y nacional diversa, una economía tambaleante y con escaso desarrollo industrial, aún afectada por las consecuencias de la guerra civil (Carr, 1979: 5059), pero con la disidencia bolchevique acallada y una camarilla de adeptos, las posibilidades solo él las determinaría.

\section{A modo de hoja de ruta}

En este momento resulta fundamental efectuar la distinción para establecer los ejes temáticos en que basaremos nuestra investigación. En primer lugar, definir nuestra intencionalidad de apartar de nuestro estudio aquellos actos que obedezcan a una lógica distinta de la simbólica y ritualística que permitieron a Stalin hacerse y mantener su poder, y que más bien se relacionan con motivaciones inmediatistas, "reformas" burocráticas, supresión de la potencial disidencia, intimidación directa o simples bravatas. Sin embargo, haremos alusión a estos actos cuando guarden relación con nuestro eje central de análisis.

Centraremos nuestra atención en aquellos actos simbólicos cuyo significado está determinado por la interpretación de quienes presencian, directa o indirectamente, el acto, acto que a su vez representa formas de autoridad anteriores respecto del ejecutante, de forma general entendidas como "comunes" entre una determinada población o nación. Dada esta relación, comprendemos el acto con la 
intencionalidad, por parte de quien actúa, de apropiarse de la forma y la potestad de la autoridad anterior.

Las implicancias de esta dinámica están ya fundadas por otros estudiosos. En primera instancia, las proposiciones de Marc Bloch en su libro Los reyes taumaturgos, en que estudia el origen y las implicancias para el poder de los reyes medievales de Inglaterra y Francia, de sus milagrosas atribuciones curativas de escrófulas. A grandes rasgos, según Bloch, la ejecución del acto curativo obedece a una lógica de preservación de las relaciones de poder y demostración del poder real que, sin embargo, no resulta una impostura como podría pensarse desde la actualidad, sino que, de cierta forma, era parte de las obligaciones del rey, en que se perpetuaba y se "fundamentaba con actos" una tradición, la cualidad divina del monarca.

Por otro lado, Ernst Kantorowicz, en Los dos cuerpos del Rey, analiza los rituales medievales que se llevaban a cabo para sortear los vacíos de poder que se producían durante el interregno, es decir, el espacio de tiempo entre el fallecimiento de un monarca y la coronación del siguiente. Permitir que ocurriera este vacío de poder podía afectar gravemente la estabilidad del reino, por lo que se intentaba establecer una continuidad, separando el cuerpo físico temporal del rey como persona y el cuerpo del rey como - en palabras más actuales_ "institución" -la corona-, que era perpetua y continua. Con ese fin se ejecutaba una serie de actos y difusión de símbolos que reflejaran esta cualidad, como la postergación de los ritos funerarios reales o la asociación del monarca a figuras mitológicas comprensibles por todos, como el Fénix.

Aunque, a primeras luces, intentar aplicar metodologías de estudios sobre la Edad Media a un caso del siglo XX pueda parecer un planteamiento forzado y anacrónico, nos parece prudente hacer algunas modificaciones y establecer, de forma somera, relaciones entre los objetos de estudio de los autores mencionados y el tema a tratar en este trabajo.

El sustento al poder de los monarcas medievales provenía desde su cualidad divina y los ritos que se efectuaban tenían como fin reafirmar y recordar dicha cualidad. Sin embargo, en la Unión Soviética las prácticas religiosas, en el sentido tradicional del término, no tenían cabida, y la postura oficial del Estado apuntaba a desalentar cualquier resabio 
de cristianismo ${ }^{2}$, en concordancia con las ideas marxistas. Se propuso entonces otra forma de "religiosidad", empleando el concepto de forma laxa. Desde el Estado soviético, el carácter teleológico y escatológico del cristianismo es sustituido por uno marxista; la cientificidad de la dialéctica y el materialismo histórico guiarían al pueblo hacia el paraíso comunista, sustituyendo la salvación extraterrenal por la búsqueda de esa salvación dentro de la secularidad (Riegel, 2005: 97-126), y se llevarían a cabo rituales y difusión de simbolismos con similitudes a los de un culto religioso.

Siguiendo ese propósito se llevaban a cabo los ritos que analizaremos, los que promuevían la idea de "cualidad divina" del líder, no por su consagración, sino por su conocimiento y apego a la doctrina marxista, en cuanto su cientificidad infalible y nomotética. La idea de "continuidad" también la encontramos en la herencia que recibió Stalin de sus "ancestros", Marx y Lenin, como forjadores de una sociedad nueva, más justa, segura e igualitaria.

\section{Marxismo, Lenin II y el vozhd'}

Para fundamentar el establecimiento y preservación del poder de Stalin, no podemos quedarnos solamente con el fenómeno de la supresión de los rivales que amenazaban su primacía o con la legitimidad per sé del cargo que detentaba. Atribuir su extenso y profundo mandato solo a esos factores sería ignorar tantos otros menos racionales y, postulamos, más potentes, vinculantes y trascendentes.

En primer lugar, la cualidad que Stalin buscaba atribuirse, en relación con el pasado, el carácter en primera instancia sucesorio y luego de encarnación respecto de la figura de Lenin. El poder que poseía Lenin, incluso estando embalsamado en la Plaza Roja, era gigantesco, pues él era el rostro visible y el artífice de la Revolución de 1917, el intelectual armado y dispuesto a la acción, preclaro en la comprensión del marxismo y del materialismo científico, cuyo legado continuaría tras su fallecimiento. El hecho de que se le haya hecho una procesión, en la que la gente cargaba "íconos" con su rostro, y sus restos preservados

La supresión de la religión ortodoxa tuvo su momento más álgido en las décadas de 1920 y 1930. El Estado soviético se volvió más permisivo durante y después de la Segunda Guerra Mundial, véase Figes (2002: 583). 
eran depositados solemnemente en un mausoleo para que sirviera de lugar de peregrinación, no solo habla de una especie de canonización del líder, sino que, según Riegel, hace gran resonancia con la inmortalidad del Rey como institución, sobreviviente in eternum al decaimiento del cuerpo físico personal, como lo plantea Kantorowicz en Los dos cuerpos del Rey (Riegel, 2005: 109). La iniciativa por parte de Stalin, de mostrarse como heredero y continuador de la obra y carácter de Lenin, puede vislumbrarse a partir del propio funeral del mandatario: en su discurso, el georgiano expresa su promesa de continuar con su obra:

"Al separarse de nosotros, el camarada Lenin nos ordenó que sostuviéramos muy alta y mantuviésemos muy pura la gran condición de miembro del partido. Nosotros te prometemos camarada Lenin, que cumpliremos honrosamente ese mandato tuyo. Al separarse de nosotros, el camarada Lenin nos ordenó que guardásemos la unidad de nuestro partido como la niña de nuestros ojos. (...) Al separarse de nosotros el camarada Lenin nos ordenó que guardásemos y reforzásemos la dictadura del proletariado. Nosotros te prometemos camarada Lenin que no ahorraremos nuestras energías para cumplir honrosamente ese mandato tuyo (...) Nosotros te prometemos, camarada Lenin, que no ahorraremos nuestras vidas con tal de reafirmar y extender la unión de la clase obrera de todo el mundo, la Internacional Comunista" (Payne, 1967: 291).

Los actos y discursos del resto del politburó facilitaron la iniciativa de $S \operatorname{lalin}^{3}$, oficializando la idea de la continuidad imperecedera del leninismo y, a la vez, permitiendo que Stalin se apropiase de la dirección de ese legado.

La imagen también jugaría un rol importante en esta idea de la relación y continuidad entre Lenin y Stalin. A partir de 1933, el diario oficial Pravda - verdad en ruso- se convertiría en el principal vehículo difusor de la cultura pictórica y fotográfica representando la efigie del georgiano (Plamper, 2012: 61). Dentro de las múltiples ocasiones en que la imagen de Stalin se publicara en la portada del diario - siempre

: "Lenin lives in the soul of every member of our party. Every member of our party is a particle of Lenin. Our entire communist family is a collective embodiment of Lenin. Lenin lives in the heart of every honest worker. Lenin lives in the heart of every poor peasant". Declaración oficial del Comité Central. Véase Tumarkin (1983: 148). 
sutilmente diferenciado respecto de quien le pudiera acompañar en la foto, posicionado adelante con naturalidad artificial, en actitud paternalista, afable, calma, sosteniendo algún niño en brazos o en compañía de obreros o agricultores-, desde 1935 las fotos incluirían también alguna persona de etnia no rusa, realzando el carácter multinacional de la Unión Soviética (Plamper, 2012: 54-77). El nexo con Lenin es palpable en las imágenes en que ambos aparecen, y que se repetirían con cierta recurrencia. En Pravda aparecen principalmente en el periodo de posguerra y con motivo del cumpleaños de Lenin o las conmemoraciones de la Revolución de 1917.

La imagen de Stalin también sirvió de inspiración y referencia para los artistas pictóricos que, a rasgos generales, continúan los mismos tópicos y alusiones a la hora de representarle, destacando su sencillez, gentileza y amor al pueblo. La relación con Lenin aparece más evidente, ya que la pintura no tiene las limitaciones de la fotografía y permite al artista representar situaciones que no necesariamente hayan ocurrido. Es más potente también la idea de Lenin como mentor de Stalin, por lo que aparece instruyéndole o a su izquierda-detrás, reforzando la idea de que primero iba Lenin y luego Stalin, insistiendo en la continuidad entre ellos (Plamper, 2012: 62).

La invocación constante a Lenin, como ya hemos explicado, se debe tanto a su rol en 1917 como a su interpretación de las verdades del marxismo, Stalin querrá hacer lo propio y, paulatinamente, desprenderse de la dependencia respecto a la figura de Lenin, asumiendo él mismo el rol de portavoz del marxismo.

Stalin nunca fue un intelectual, sus intentos de escribir obras de carácter filosófico o sobre teoría marxista antes de llegar al poder no causaron demasiado revuelo ${ }^{4}$; sin embargo, una vez en el poder aprovecharía para establecerse como un teórico brillante y con una comprensión notable de la teoría marxista. Para la Unión Soviética, el poder asociado a la teoría marxista se encuentra en su naturaleza explicativa y nomotética de los fenómenos, la historia y el porvenir. La dialéctica, el materialismo, la lucha de clases, junto con las contradicciones y vicios del modo de pro-

En 1913, Stalin escribe El Marxismo y la cuestión nacional, analizando el origen de la idea de "nación" y postulando que no tiene sustento significativo: las naciones no existirían, solo la comunidad internacional de los obreros. Véase Payne (1967: 122-124). 
ducción capitalista, se entendían como verdades evidentes e inmutables, el fundamento mayor para la Revolución y el socialismo en su carácter mesiánico, justo y redentor (Riegel, 2005: 99-101).

Stalin se sirvió de algunos profesores oportunistas, que desarrollaron la idea de un discurso de éste, en 1929, en una conferencia de marxistas agrarios, sobre la praxis del marxismo. Los profesores Iudin, Mitin y Ral'tsevich publicaron los resultados de esa investigación atribuyendo a la genialidad de Stalin el germen de sus ideas (Tucker, 1979: 350-351). Posteriormente, Stalin asumiría el rol de gran intérprete de la teoría marxista mediante sus propias publicaciones, concediendo un aspecto pragmático a sus planteamientos, denunciando las "deformaciones" de Bujarin y Plejanov, que hasta ese momento eran considerados también, fieles discípulos de Lenin. Ahora sus ideas pasaron a ser heréticas, menchevizantes y erróneas (Tucker, 1979: 352-353).

Otra forma de fundamentar su compromiso y continuidad era a través de la modificación y deformación de la historia, reescribiendo obras para introducir y modificar hechos de formas que nunca ocurrieron. Objeto especial de este tratamiento fueron las obras de Lenin y la historia del partido bolchevique. Los escritos de Lenin fueron modificados para que pareciera menos tolerante a las desviaciones y reinterpretaciones, como las de Bujarin y Plejanov. La deformación histórica principalmente pretendía exacerbar el rol que tuvo Stalin durante el periodo previo a la Revolución de 1917. Las desviaciones más graves fueron las publicadas en 1938 como Historia del Partido Comunista de la Unión Soviética: Breve Curso. Allí se afirmaba que Lenin recibió la autorización de Stalin para la publicación de Iskra (chispa), el primer periódico bolchevique y que la Conferencia de Praga de 1912 era un hecho esencial para la revolución, solo porque allí fue el nombramiento de Stalin como Secretario General (Laqueaur, 2003: 221). Este actuar denota la intencionalidad del georgiano por adquirir independencia, aunque perpetuando la relación con la figura de Lenin, ya no presentándose como el más aventajado de sus discípulos, sino en una relación simétrica con este, atribuyéndose la cualidad del vozhd' ya encarnada por Lenin, como líder con cualidades sobrehumanas, de sencillez, humanidad, empapado en la esencia popular y de gran poder (Bonell, 1997: 142).

Quizá lo más tristemente célebre del mandato de Stalin fueran las purgas, ejecuciones sistemáticas de supuestos disidentes, heterodoxos 
y terroristas, que confesaban su "crimen" tras una serie de torturas y trato infrahumano. Durante los periodos de la Revolución y la Guerra Civil, existió el antecedente de lo que posteriormente se convertiría en una auténtica maquinaria destinada al exterminio masivo. Entre 1917 y 1928 existía un terror desorganizado, en que se infringían graves vejaciones y asesinatos a quienes fueran declarados enemigos de la causa, pero la desorganización implicaba que, en el fondo, sin deliberación, toda la población corría el riesgo de morir horriblemente (Payne, 1967: 359-361).

En 1928 Stalin establecería la chistka - se suele traducir como "purga" o "limpieza" -, esto es, la práctica de asesinar a miles de personas bajo el amparo de la institucionalidad del Estado, junto al brazo armado y servil de la NKVD ${ }^{5}$. Las purgas tendrían su nadir entre 1937-38 y no culminarían hasta la muerte del Secretario General (Payne, 1967: 362363). El proceso era especial cuando el acusado era una personalidad pública, alto funcionario o veterano bolchevique. En esos casos era sometido a un juicio público, en el que confesaba toda clase de crímenes innombrables y era obligado a doblegarse, tras ser sometido a tortura fuera de la vista pública (Payne, 1967: 358). El propósito de las purgas, más allá de la intimidación directa y eliminación de la competencia para Stalin, era de naturaleza ritual, con el fin de conceder al Estado soviético - y a su dirigente- el carácter virtuoso de estar en una lucha constante contra el mal, materializado en terroristas, heterodoxos, saboteadores, trotskistas y espías, y a la vez encontrar un chivo expiatorio para culparlo de todos los problemas económicos de la Unión Soviética (Riegel, 2005: 115). En el fondo, era una forma distorsionada de materializar la lucha de clases, necesaria para el advenimiento del comunismo, una especie de dramatización sanguinaria para buscar y ajusticiar enemigos que no existían, justificando la existencia del Estado, el rol de Stalin y su apego a los planteamientos de Lenin y Marx. Dado su aspecto reiterativo y premeditado ${ }^{6}$, y su significación más allá de lo inmediato, nos permitimos atribuir la cualidad de "ritual" a las purgas.

Comisariado del Pueblo para Asuntos Internos, en términos actuales "policía secreta".

Eran habituales los telegramas entre los altos mandos de la NKVD del tipo "Queda encargado del exterminio de diez mil enemigos del pueblo", estableciéndose metas en las cifras de procesados. Véase Payne (1967: 363). 


\section{El rey ha muerto. ¿Qué viva el rey?}

Una vez falleció Stalin, las prácticas más terribles de su mandato cesaron inmediatamente. El último intento de purga, el episodio de 1953 denominado "La conjura de los médicos", en que se acusó a altos cargos de instituciones médicas de suministrar tratamiento nocivo a los pacientes, quedó a medio camino. Uno de los procesados, el doctor Vladimir Vinogradov, una de las más altas autoridades de la Unión Soviética, alcanzó a sobrevivir la tortura y evitar su ejecución (Payne, 1967: 564-570).

Sin embargo, un fenómeno curioso de la muerte de Stalin fue la iniciativa, por parte del alto mando restante, de intentar evitar el interregno y el caos que podía producirse tras su muerte: nadie se atrevía a gobernar. Conforme empeoraba su estado de salud, las noticias que emanaban de Radio Moscú eran confusas. Las circunstancias acerca de las causas de su fallecimiento no están del todo claras; la versión más aceptada es la de la hemorragia cerebral, aunque se baraja la posibilidad de que haya sido envenenado (Payne, 1967: 588-595). El 24 o 25 de febrero Stalin queda "incapacitado", apenas el 6 de marzo se haría el comunicado oficial al público, entre confusiones, escaramuzas por el poder y la cobardía por parte de lo que restaba de su camarilla. Fue la consecuencia de haber constituido su alto mando con individuos serviles, pero inadecuados para los cargos que detentaban.

Aunque se hayan detenido las purgas, era imperativo para la Unión Soviética un proceso de restauración de la verdad y la condena al estalinismo, un proceso complejo e incompleto. Si bien, en rasgos generales, se admitía lo perjudicial y sanguinario del periodo, cerrar las heridas implicaba necesariamente remover dolorosamente la pústula de las vejaciones acaecidas en los tiempos de Stalin. Su sucesor inmediato, Nikita Jruschev, lo intentó y denunció los crímenes del estalinismo en 1956, durante el XX Congreso del Partido Comunista de la Unión Soviética (Payne, 1967: 599-600), condenando el culto al individuo, el carácter de Stalin, la represión y los juicios públicos. En 1961 habló ante el XXII Congreso del Partido la revolucionaria y víctima de la represión estalinista Dora Abramovna Lazurkina

“Mi corazón está siempre lleno de Lenin (...) pude sobrevivir a los trances más difíciles solamente porque llevaba a Lenin en mi co- 
razón y siempre le consultaba lo que tenía que hacer. Ayer le consulté. Lenin estaba de pie delante de mí, como si estuviera vivo y me dijo: 'Es desagradable encontrarse al lado de Stalin, quien hizo tanto daño al partido"'.

Los aplausos encabezados por Jruschev fueron efusivos y la anciana acaparó la atención de los medios. Inmediatamente, Jruschev ordenó la remoción del cadáver de Stalin del mausoleo, sin ceremonia y de noche. Ahora, sus restos yacen bajo una de las murallas del Kremlin, sin guardias ni médicos (Payne, 1967: 602-603).

Sin embargo, otros aspectos del legado de Stalin mantienen en cierta forma su continuidad. La iniciativa de Jruschev no tuvo toda la aprobación que ameritaba y se le destituyó deshonrosamente. Su sucesor, Léonid Brezhnév, intentó emular una versión descafeinada del culto a la personalidad (Gill, 1980: 167-186). Debió asumir Mijaíl Gorbachov y echar a correr la glásnost de 1988 para ver los esfuerzos más notables de asumir los errores y la condena al estalinismo; se publicaron las crudas novelas de Grossman y Solzhenitsin sobre la represión y los gulagi; se permitió también la crítica, incluso contra Lenin (Laqueaur, 2003: 322-323), pero aún queda trabajo que hacer. Actualmente Rusia atraviesa una serie de fenómenos que, a su manera, tienen ciertos aires que podrían rememorar a Stalin: la relevancia en el poder de Vladimir Putin, que desde el año 2000 cumple un rol central en la dirección política rusa (Sawka, 2004: 2533). Criticado por su conservadurismo, populismo, prepotencia en relaciones internacionales y por evadir reformas sociales contra la desigualdad social; aun así, se ha mantenido en un rol central. Quizá sea aventurado señalar resabios de estalinismo, pero tampoco puede descartarse.

Existen otros vestigios más evidentes. Una encuesta de 2017 arrojó que un $46 \%$ de los encuestados tenía una actitud positiva hacia Stalin ${ }^{7}$, mientras que miembros del Partido Comunista Ruso aún rinden

Adam Taylor. "Positive views of Stalin among Russians reach 16-year high, poll shows". The Washington Post. Feb. 15, 2017. Recuperado de https://www.washingtonpost.com/news/worldviews/wp/2017/02/15/positive-views-of-stalin-among-russiansreach-16-year-high-poll-shows/?noredirect=on\&utm_term=.94914f19d654, revisado el 23-VII-2019. 
homenaje al georgiano ${ }^{8}$. Ni la cultura pop se ha librado de su influjo. Existen actualmente cientos de parodias, homenajes y ficciones basadas en su figura; hasta es posible comprar en Amazon unas matrioshkas con la efigie de Stalin, Lenin y Marx. Sus actos, destinados a perpetuarse, continúan teniendo resonancia hasta el día de hoy, confirmando la cruel efectividad de los mismos.

\section{Referencias Bibliográficas}

\section{Fuentes Secundarias}

a) Artículos y capítulos de libros

Gill, G. (1980). “The Soviet Leader Cult: Reflections on the Structure of Leadership in the Soviet Union", in British Journal of Political Science, vol. 10, $\mathrm{N}^{\circ}$ 2, pp. 167-186.

Riegel, K. (2005). “Marxism-Leninism as a Political Religion”, en Totalitarian Movements and Political Religions, vol. 6, $\mathrm{N}^{\circ} 1$, pp. 97126.

Tucker, R. (1979). “The Rise of Stalin's Personality Cult", en The American Historical Review, vol. 84, N², pp. 347-366.

b) Libros

Bloch, M. (2006). Los Reyes Taumaturgos: Estudio sobre el carácter sobrenatural atribuido al poder real, particularmente en Francia e Inglaterra. México D.F.: Fondo de Cultura Económica.

Bonell, V. (1997). Iconography of Power: Soviet Political Posters under Lenin and Stalin. Berkeley: University of California Press.

Carr, E. (1979). The Russian Revolution: From Lenin to Stalin. Nueva York: The Free Press.

Figes, O. (2002). El baile de Natacha. Una historia cultural rusa. Barcelona: Edhasa.

Kantorowicz, E. (2012). Los dos cuerpos del Rey: Un estudio de teología medieval, Madrid: Akal.

Kenez, P. (2006). A history of the Soviet Union from the beginning to the end. Cambridge: Cambridge University Press. 
Laqueaur, W. (2003). Stalin: La estrategia del Terror. Barcelona: Ediciones B.

Lourie, R. (2001). Stalin: La novela. Barcelona: Planeta.

Payne, R. (1967). Stalin. Barcelona: Bruguera.

Plamper, J. (2012). The Stalin Cult: a study in the alchemy of power. New Haven: Yale University Press.

Sakwa, R. (2004). Putin: Russia's Choice. London: Routledge.

Tumarkin, N. (1983). Lenin Lives! The Lenin Cult in Soviet Russia. Cambridge: Harvard University Press.

c) Otros

"Comunistas rusos en Moscú rindieron homenaje a Iosif Stalin en el $140^{\circ}$ aniversario de su natalicio", Newsfront, 21-XII-2019, https://es.news-front.info/2019/12/21/comunistas-rusos-en-moscu-rindieron-homenaje-a-iosif-stalin-en-el140-aniversario-de-su-natalicio-fotos-video/, revisado el 23-IV-2020.

“Nesting Doll-Russian Leaders (6'75)", Amazon, https://www.amazon. com/craftsfromrussia-Nesting-Doll-Russian-Leaders/dp/ B06XQN98Z1/ref=pd_lpo_sbs_21_img_0?_encoding=UTF 8\&psc=1\&refRID=YGMGVBE69CVC29XKY0YA, revisado el 23-VII-2019.

"Positive views of Stalin among Russians reach 16-year high, poll shows", The Washington Post, 15-II-2017 en: https://www.washingtonpost.com/news/worldviews/wp/2017/02/15/positiveviews-of-stalin-among-russians-reach-16-year-high-pollshows/?noredirect $=$ on\&utm_term $=.94914 \mathrm{f} 19 \mathrm{~d} 654$, revisado el 23-VII-2019.

"Thousands pay respects to Stalin", $B B C$, 06-III-2003 en: http://news. bbc.co.uk/2/hi/europe/2822029.stm, revisado el 23-VII2019. 